\title{
Effect of Fermentation Containers and Raw Materials on Chemical Composition and Sensory Quality of fermented cereals
}

\author{
Dhan B. Karki and Ganga P. Kharel \\ Central Campus of Technology Tribhuban University, Hattisar, Dharan \\ e-mail: karkidhan@yahoo.com
}

\begin{abstract}
Effect of fermentation containers (plastic, wooden and earthen), cereals (millet, rice, maize and wheat) and cereal combinations (millet, rice and wheat) on chemical and sensory quality of fermented cereals were studied. Fermentation was carried out for 15 days at $26 \pm 2{ }^{\circ} \mathrm{C}$ using defined starter made from S. cerevisiae and $R$. oryzae in rice flour. Finger millet fermented in plastic container had higher alcohol content $(15.81 \% \mathrm{v} / \mathrm{m})$ and TSS $\left(11.96^{\circ} \mathrm{Bx}\right)$ than that of earthen container while moisture and fixed acid contents remained unaffected. Total esters ( $1.813 \mathrm{~g} / \mathrm{l} \mathrm{alc})$, total aldehyde $(0.850 \mathrm{~g} / \mathrm{l}$ alc), total acidity $(1.58 \% \mathrm{~m} / \mathrm{m})$ and volatile acidity $(0.296 \% \mathrm{~m} / \mathrm{m})$ were higher in millet fermented in earthen container. Fermentation containers had no significant ( $\mathrm{p}>0.05)$ effect on the taste and smell of millet jand but color was comparatively superior in plastic container. Total ester ( $31.1 \mathrm{mg} \% \mathrm{~m} / \mathrm{v}$ ), TSS ( $3.97^{\circ} \mathrm{Bx}$ ), $\mathrm{pH}(4.67)$, total acid $(0.41 \% \mathrm{~m} / \mathrm{v}))$ and fixed acid $(0.37 \% \mathrm{~m} / \mathrm{v})$ contents were significantly higher in wheat jand compared to millet, rice, and maize jands, whereas no noticeable difference in volatile acidity $(0.02-0.048 \% \mathrm{~m} / \mathrm{v})$ and alcohol (5.53$6.20 \% \mathrm{v} / \mathrm{v}$ ) contents were found among four jands. Sensory evaluation showed that taste and smell of rice jand were superior (liked very much) while that of maize was rated as dislike slightly by the panelists. Addition of rice significantly increased the TSS of fermented millet while total acidity, fixed acidity and alcohol contents were not affected by cereal combinations. Addition of wheat decreased the ester content $(0.431 \mathrm{~g} / \mathrm{l}$ alc) to that of control $(100 \%$ millet $)(0.863 \mathrm{~g} / \mathrm{L}$ alc). Total aldehyde content was significantly increased by both rice and wheat addition with a maximum value of $1.545 \mathrm{~g} / \mathrm{l}$ alc in $20 \%$ rice added fermented millet. Finger millet substituted with $20 \%$ of rice had the maximum fusel oil $(9.370 \mathrm{~g} / \mathrm{l}$ alc $)$ while a minimum value of $5.297 \mathrm{~g} / \mathrm{l}$ alc was found in $20 \%$ wheat substituted fermented millet. Cereal combination did not have significant effect on methanol content and the values were in the range of $2.346-3.858 \mathrm{~g} / \mathrm{L}$ alc. Addition of rice significantly increased the reducing and total sugar contents while $20 \%$ wheat addition decreased both the reducing and total sugar contents in fermented millet. Sensory evaluation revealed that cereal combination did not affect the color preference of jands, whereas addition of wheat significantly impaired the taste and smell of jand.
\end{abstract}

Key words: alcohol, aldehyde, cereal fermentation, ester, fusel oil, methanol

\section{Introduction}

Indigenous food fermentation is one of the oldest food biotechnological processes dependent on the biological activity of microorganisms from which development of fermented foods is achieved in the cultural history of human beings (Ross et al., 2002).
The process of cereal alcoholic fermentation using mold starter was well established in the year of 1,000 $\mathrm{BC}$ and 43 different types of cereal wines and beers were described with detail processing in Chi-Min-YoaShu, where millet appeared to be the main cereal for 
alcoholic fermentation (Yoon 1993). Traditional method of rice brewing was industrialized by Japanese brewers in the late 19th century who adopted pure starter culture manufacturing technology from Europe and transferred it to Korea and China (Lee \& Kim 1993).

Jand is an alcoholic beverage indigenous to Nepal. It is prepared by solid-state fermentation of starchy raw materials like maize (Zea mays), rice (Oryza sativa), wheat (Triticum spp.), and finger millet (Eleusine coracana). The basic steps followed in the traditional cereal fermentation are: cooking of the prepared cereal, cooling of the cooked mass to room temperature, mixing with murcha powder (a traditional fermentation starter), leaving for 1 to 2 days for biomass build up and alcoholic fermentation. Originally, closed-necked earthen pots were used for fermentation but nowadays plastic containers have largely replaced them. Of the various cereals used, finger millet has been the raw material of choice due to its low price, clean flavor and aroma of the brew. Moreover, the grain can remains discrete for a longer period of time. Fermented millet is believed to posses certain curative values (the fermented mash is supposed to relieve pain when applied over the areas stung by bees and wasps (Rai 1991).

Traditionally, cereal fermentation is carried out in earthen or plastic containers using single cereal. Sometimes, finger millet is supplemented with small amount of other cereals, viz., rice or wheat or both, mainly if it is intended for jand and tongba making. It is said that addition of small amount of rice or wheat help to increase the taste and mouth feel of the jand and tongba, but data supporting to this notion is still lacking. Information regarding the effect of fermentation container on the quality of millet jand, quality comparison among jand prepared from different cereals and effect of cereal combination on the chemical and sensory quality of fermented mash is scanty. Hence, the main objectives of this work are to seek the answers to the above questions.

\section{Materials and Methods \\ Preparation of fermentation starter}

Fermentation starter was prepared using yeast (Saccharomyces cerevisiae) and mold (Rhizopus oryzae) isolated from traditional starter (murcha) in PDA supplemented with $100 \mathrm{ppm}$ of chloramphenicol. Yeast was grown in molasses broth of $6^{\circ} \mathrm{Bx}$ TSS for 3 days at 27 ${ }^{\circ} \mathrm{C}$ and kept in refrigerator until used. Mold bran was prepared by inoculating isolated mold in sterile wheat bran, incubating for 5 days at $30^{\circ} \mathrm{C}$, drying at $24^{\circ} \mathrm{C}$ for 12 $\mathrm{h}$ and then packed in sterile glass bottle. Yeast (from molasses broth) and mold (from mold bran) were added to sterile rice flour, mixed with the addition of required amount of sterile distilled water and the dough was divided into small balls. The balls were flattened, placed in a sterile petri plate, incubated at $30^{\circ} \mathrm{C}$ for 3 days and dried at $40^{\circ} \mathrm{C}$ for $24 \mathrm{~h}$.

\section{Cereal fermentation}

Finger millet (coracana, brown variety) was collected from local market of Dharan, dry cleaned, dehusked and washed thoroughly with water. It was then steeped in water for $2 \mathrm{~h}$, cooked, and spread on aluminum tray to cool to room temperature. Fermentation starter powder was added to the cooked millet at the rate of $1 \mathrm{~g}$ per $100 \mathrm{~g}$ of millet, mixed thoroughly, covered with wet muslin cloth and allowed to undergo biomass development for 2 days at $30^{\circ} \mathrm{C}$. Then the millet was filled into different fermentation containers viz., plastic, wooden and earthen, and kept for alcoholic fermentation for 15 days at $26^{\circ} \pm$ $2^{\circ} \mathrm{C}$. After fermentation, the samples were analyzed for chemical and organoleptic characteristics.

In order to study the effect of different cereals on the chemical and sensory quality of the fermented products, different cereals viz., millet, rice, wheat and maize were fermented in plastic containers and their chemical and sensory quality were analyzed. Similarly, effect of rice and wheat addition on the quality of fermented millet was also studied. For this, rice and wheat were mixed with finger millet in different proportions [100\% millet (M), $80 \%$ millet $+20 \%$ rice (MR), $80 \%$ millet $+20 \%$ wheat (MW) and $80 \%$ millet $+10 \%$ rice $+10 \%$ wheat (MRW)], fermented in plastic containers as described earlier and their chemical and sensory characteristics were analyzed.

\section{Analytical procedure}

Total soluble solids (TSS) was determined by using hand refractometer ( $\left(0-32^{\circ} \mathrm{Bx}\right.$, Hanna Instrument, Portugal). $\mathrm{pH}$ was determined by using portable $\mathrm{pH}$ meter (Hanna Instrument, Portugal). Moisture content was determined by oven drying method as per Ranganna (1986). Total, fixed and volatile acidities; total esters and total aldehyde contents were determined according to Kirk and Sawyer (1991). Alcohol content was determined by visible spectrometric - dichromate oxidation method as per Zoecklein et al. (1997). Reducing and total sugars were determined by Lane and Eynon method as per 
Dhan B. Karki \& ganga P. Kharel/Effect of Fermentation.......

Ranganna (1986). Fusel oil and methanol contents in the distillate were determined by spectrophotometric and chromotropic acid colorometric methods respectively as per AOAC (2005).

\section{Sensory evaluation}

jand was prepared by mixing 1 part of fermented cereal to each 1.5 parts of water $(\mathrm{m} / \mathrm{v})$. The mixture was gently mixed and allowed to stand for $20 \mathrm{~min}$ and then strained through a plastic net. Sensory evaluation of the jands was carried out by using hedonic rating test as per Ranganna (1986). Ten semi-trained panelists consisting of administrative staffs, faculties and students of the college were ask to rate the acceptability of the product on a 9- point scale ranging from 1 ('dislike extremely') to 9 ('like extremely') in terms of color, taste and smell of the product.

\section{Statistical analysis}

The experiment was conducted in a RCBD with three replications. Experimental data were analyzed by analysis of variance (ANOVA) and means were compared by LSD method as per Buysse et al. (2007).

\section{Results and Discussion}

Effect of fermentation containers on chemical and sensory quality of fermented finger millet The chemical characteristics of millet fermented in plastic, wooden and earthen containers were analysed and the results are shown in Table 1 . The moisture content of fermented millet was in the range of 75.23 $76.42 \% \mathrm{~m} / \mathrm{m}$. Statistical analysis revealed that fermentation container had no significant effect ( $>>0.05$ ) on the moisture content of fermented millet. Millet fermented in plastic container had significantly higher $(\mathrm{p}<0.05)$ TSS than those of wooden and earthen whereas the values between the latter two did not differ. Both total and volatile acidities were higher in millet fermented using earthen container but the values between plastic and wooden containers did not differ significantly ( $p>0.05$ ). No significant difference in the fixed acidity was found among the three samples. Higher amounts of total and volatile acidities in the earthen container could be due to the incorporation of air through the pores of the container during fermentation. Alcohol contents between plastic $(15.81 \% \mathrm{v} / \mathrm{m})$ and wooden $(14.21 \% \mathrm{v} / \mathrm{m})$ containers were not different but it was significantly lower (11.21 $\% \mathrm{v} / \mathrm{m}$ ) in earthen container. This lower alcohol content in earthen container could partly justify for the increased total and volatile acidities owing to the oxidation of alcohol. Millet fermented in earthen container had the highest total ester content (1.831 g/ $\mathrm{L}$ alc as ethyl acetate) of all the containers used but the values between plastic and wooden containers were statistically similar. Total aldehyde contents, as acetaldehyde, were found to be $0.20,0.577$ and 0.850 $\mathrm{g} / \mathrm{L}$ alc) in millet fermented using plastic, wooden and earthen containers respectively and statistically the values were significantly different from each other.

Table 1. Effect of fermentation container on chemical characteristics of fermented millet

\begin{tabular}{|c|c|c|c|}
\hline \multirow[b]{2}{*}{ Parameters } & \multicolumn{3}{|c|}{ Values for different containers* } \\
\hline & Plastic & Wooden & Earthen \\
\hline Moisture content, \% m/m & $75.43^{\mathrm{a}}(0.74)$ & $76.42^{\mathrm{a}}(0.75)$ & $75.23^{\mathrm{a}}(0.27)$ \\
\hline Total soluble solids (TSS), ${ }^{\circ} \mathrm{Bx}$. & $11.96^{\mathrm{a}}(0.92)$ & $9.70^{\mathrm{b}}(0.61)$ & $8.39^{\mathrm{b}}(0.62)$ \\
\hline Total acidity as lactic, $\% \mathrm{~m} / \mathrm{m}$ & $1.05^{\mathrm{a}}(0.09)$ & $1.10^{\mathrm{a}}(0.13)$ & $1.58^{\mathrm{b}}(0.32)$ \\
\hline Fixed acidity as lactic, $\% \mathrm{~m} / \mathrm{m}$ & $0.94^{\mathrm{a}}(0.08)$ & $1.00^{\mathrm{a}}(0.14)$ & $1.18^{\mathrm{a}}(0.28)$ \\
\hline Volatile acidity as acetic, $\% \mathrm{~m} / \mathrm{m}$ & $0.075^{\mathrm{a}}(0.006)$ & $0.069^{\mathrm{a}}(0.001)$ & $0.296^{\mathrm{b}}(0.014)$ \\
\hline Alcohol, \% v/m & $15.81^{\mathrm{a}}(0.66)$ & $14.21^{\mathrm{a}}(0.54)$ & $11.21^{\mathrm{b}}(1.23)$ \\
\hline Total esters as ethyl acetate, g/l alcohol & $0.787^{\mathrm{a}}(0.140)$ & $0.912^{\mathrm{a}}(0.075)$ & $1.831^{\mathrm{b}}(0.427)$ \\
\hline Total aldehydes as acetaldehyde,g/l alcohol & $0.200^{\mathrm{a}}(0.006)$ & $0.577^{\mathrm{b}}(0.01)$ & $0.850^{\mathrm{c}}(0.071)$ \\
\hline
\end{tabular}

*: Values are the means of three replications. Figures in the parentheses are the standard deviations. Means followed by the same superscripts in a row are not significantly different $(p>0.05)$ by LSD 
Effect of fermentation containers on the sensory quality of millet jand is depicted in Fig.1. The mean sensory scores for colour, taste and smell, out of a total possible score of 9, were found to be 8.33, 7.50 and 6.83; 7.83, 7.67 and 7.17; and 7.50, 7.83 and 7.00 for millet fermented in plastic, wooden and earthen containers respectively. Statistical analysis showed that fermentation container had a significant effect on the colour, whereas taste and smell were not affected. LSD indicated that the mean colour preference scores between plastic and wooden and between wooden and earthen containers did not differ, but it was different between plastic and earthen containers. Plastic containers are easy to clean and handle compared to wooden and earthen ones. Results of chemical and organoleptic analyses of fermented millets revealed that no remarkable improvement on the chemical and sensory quality was found using wooden and earthen containers over the plastic container. Hence, plastic containers could be regarded as an appropriate container for millet fermentation.

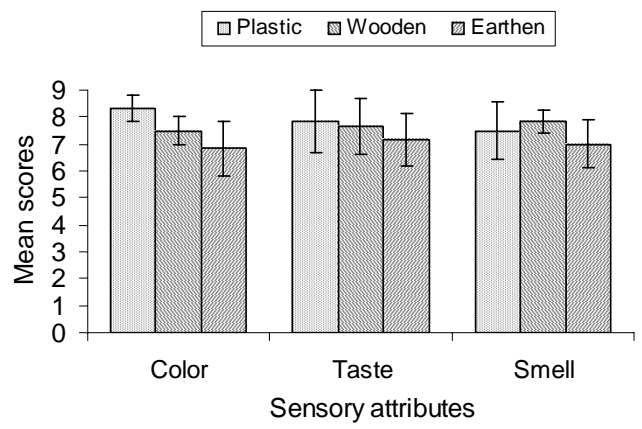

Fig. 1. Effect of fermentation containers on the sensory quality of jands.*

$*$ : Values are the means $(\mathrm{n}=10) \pm S D$. Bars having different letters for any quality attributes are significantly different $(p<0.05)$ by LSD.

\section{Effect of raw materials on the chemical and sensory quality of jands}

Jands were prepared from fermented millet, rice, maize and wheat by mixing 1 part of fermented cereal to each 1.5 parts of water and subjected for chemical and sensory analyses. Chemical characteristics of different jands are shown in Table 2. Jand yield was found in the order of rice $>$ maize $>$ wheat $>$ millet. Wheat jand had the highest TSS $\left(3.97^{\circ} \mathrm{Bx}\right)$ followed by millet $\left(3.27^{\circ} \mathrm{Bx}\right)$, whilemaize gave the lowest TSS of $2.03^{\circ} \mathrm{Bx}$ which was statistically similar to that of rice $\left(2.10^{\circ} \mathrm{Bx}\right)$. Raw materials showed a significant effect $(\mathrm{p}<0.05)$ on the $\mathrm{pH}$ of jand. Wheat jand had the maximumpH (4.67) whereas a minimum $\mathrm{pH}$ of 3.90 was recorded in rice jand. The $\mathrm{pH}$ values between millet and maize and between rice and maize jands were statistically not different. Total acidity was found to be $0.33,0.24,0.26$ and $0.41 \% \mathrm{~m} / \mathrm{v}$ as lactic acid in millet, rice, maize and wheat jands respectively. Statistically, wheat resulted the highest total acidity of all the cereals. Millet jand had higher total acidity compared to rice and maize but no significant difference was found between the latter two samples. A similar pattern to that of total acidity was also observed for fixed acidity of the jands but no significant difference in volatile acidity was found among four jand samples. Moisture contents of rice $(98.44 \% \mathrm{~m} / \mathrm{v})$ and maize $(98.30 \% \mathrm{~m} / \mathrm{v})$ jands were significantly higher $(\mathrm{p}<0.05))$ compared tomillet $(96.33 \% \mathrm{~m} / \mathrm{v})$ and wheat $(95.93 \%$ $\mathrm{m} / \mathrm{v}$ ) but the values between the former two and between latter two samples were not different. Total ester contents (as ethyl acetate) were found to be 10.6, 15.9, 26.5 and $31.1 \mathrm{mg} \%$ $(\mathrm{m} / \mathrm{v})$ in millet, rice, maize and wheat jands respectively and the values were significantly different from each other. The ester content of wheat jand was about 3-folds the ester content of millet and 2- folds the ester content of rice jands. Alcohol content was in the range of 5.53-6.20\%(v/v) but the values were statistically not different among four jand samples.

Table 2. Chemical characteristics of jands prepared from different cereals

\begin{tabular}{lrrrr} 
& \multicolumn{3}{c}{ Values for different fermented cereals* } \\
\cline { 2 - 5 } Parameters & \multicolumn{1}{c}{ Millet } & \multicolumn{1}{c}{ Rice } & \multicolumn{1}{c}{ Maize } & Wheat \\
\hline Jand yield (\% v/m) & $182.33^{\mathrm{a}}$ & $233.73^{\mathrm{b}}$ & $221.23^{\mathrm{c}}(1.25)$ & $202.70^{\mathrm{d}}(6.95)$ \\
& $(3.06)$ & $(7.34)$ & & \\
TSS $\left({ }^{\circ} \mathrm{Bx}\right)$ & $3.27^{\mathrm{a}}(0.06)$ & $2.10^{\mathrm{b}}(0.17)$ & $2.03^{\mathrm{b}}(0.06)$ & $3.97^{\mathrm{c}}(0.06)$ \\
pH & $4.17^{\mathrm{a}}(0.12)$ & $3.90^{\mathrm{b}}(0.17)$ & $4.10^{\mathrm{ab}}(0.1)$ & $4.67^{\mathrm{c}}(0.12)$ \\
Total acidity, as lactic acid (\% m/v) & $0.33^{\mathrm{a}}(0.01)$ & $0.24^{\mathrm{b}}(0.01)$ & $0.26^{\mathrm{b}}(0.01)$ & $0.41^{\mathrm{c}}(0.02)$ \\
Fixed acidity, as lactic acid $(\% \mathrm{~m} / \mathrm{v})$ & $0.26^{\mathrm{a}}(0.02)$ & $0.21^{\mathrm{b}}(0.01)$ & $0.22^{\mathrm{b}}(0.01)$ & $0.37^{\mathrm{c}}(0.03)$ \\
Volatile acidity, as acetic acid $(\%$ & $0.048^{\mathrm{a}}$ & $0.020^{\mathrm{a}}$ & $0.027^{\mathrm{a}}(0.007)$ & $0.025^{\mathrm{a}}(0.004)$ \\
m/v) & $(0.025)$ & $(0.001)$ & & \\
Moisture content $(\% \mathrm{~m} / \mathrm{v})$ & $96.33^{\mathrm{a}}$ & $98.44^{\mathrm{b}}$ & $98.30^{\mathrm{b}}(0.31)$ & $95.93^{\mathrm{a}}(0.33)$ \\
& $(1.07)$ & $(0.31)$ & & \\
Ester content $(\mathrm{mg} \%, \mathrm{~m} / \mathrm{v})$ & $10.6^{\mathrm{a}}(0.85)$ & $15.9^{\mathrm{b}}(0.8)$ & $26.5^{\mathrm{c}}(0.53)$ & $31.1^{\mathrm{d}}(0.77)$ \\
Alcohol content $(\% \mathrm{v} / \mathrm{v})$ & $6.20^{\mathrm{a}}(0.75)$ & $5.86^{\mathrm{a}}(0.59)$ & $5.53^{\mathrm{a}}(0.41)$ & $6.14^{\mathrm{a}}(0.9)$ \\
\hline
\end{tabular}

* Values are the means of three replications. Figures in the parentheses are the standard deviations. Means followed by different superscripts in a row are significantly different $(\mathrm{p}<0.05)$ by LSD 
Analogous results of $\mathrm{pH}(3.8$ - 4.1) and volatile acidity $(0.03-0.06 \% \mathrm{~m} / \mathrm{v}$ as acetic acid) but a higher total acidity $(0.4-0.6 \% \mathrm{~m} / \mathrm{v}$ as lactic acid) and lower alcohol content $(2.5-3 \% \mathrm{v} / \mathrm{v})$ compared to those obtained in this study were reported by Venkataramu and Bassapa (1993) in finger millet chhang. Similar results of pH and alcohol contents in millet, rice, maize and wheat jands prepared using fermented cereal to water ratio of 1:1 (m/v) were also reported by Upadhyaya (2005a), while total-, fixed- and volatile acidities and TSS were reported to be higher than those found in this study. Total ester contents found in this study were higher than those reported by Upadhyaya (2005a) and Rai (2006). Berry and Watson (1987) reported that total ester contents below $200 \mathrm{mg} / \mathrm{L}$ may be desirable but above this level appears to give a spoiled character to the wine. Peynaud (1937) suggested a minimum ethyl acetate level of $220 \mathrm{mg} / \mathrm{l}$ of wine. Amerine and Cruess (1960) reported that ethyl acetate levels of 150 - 200 $\mathrm{mg} / \mathrm{L}$ of wine impart spoilage character to the wine. Based on the available literature, millet and rice jands seemed to contain total ester within the acceptable levels while those of maize and wheat jands had a bit higher ester contents.

The results of sensory evaluation of different jand samples are shown in Fig. 2. The mean color scores for millet, rice, maize and wheat jands ,out of a total possible score of 9, were 7.25, 7.50, 6.00 and 5.75 respectively. Statistically, the colour scores between millet and rice and between maize and wheat jands were similar but the colour scores of millet and rice jands were significantly higher than those of maize and wheat samples. The mean sensory scores for taste were 7.5, 8.63, 4.75 and 6.63 for millet, rice, maize and wheat jands respectively and the values were significantly different from each other. Maize jand had the least taste preference (rated as dislike slightly) while rice had the highest taste preference (rated as like very much). The mean smell scores were $7.37,8.13$, 4.88 and 6.75 for jands made from millet, rice, maize and wheat respectively. Statistically, the effect of cereals on the smell of jand was significant and the mean scores were significantly different from each other. Again, maize jand had the least smell preference whereas rice jand had the highest smell preference.

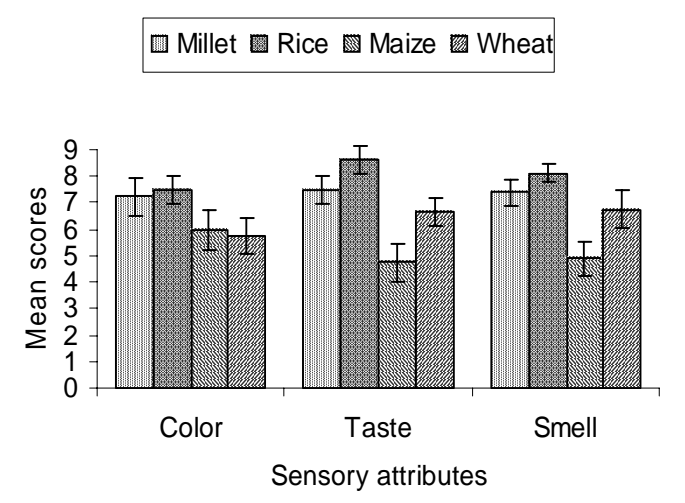

Fig. 2. Effect of cereals on the sensory quality of jand*. $*$ : Values are the means $(n=10) \pm S D$. Bars having different letters for any quality attributes are significantly different $(\mathrm{p}<0.05)$ by LSD

\section{Effect of cereal combinations on the chemical and sensory characteristics of fermented cereals.}

Four lots of fermented millet samples were prepared by substituting millet with rice (20\%), wheat (20\%) and rice + wheat (10\% each) and analyzed for chemical and sensory quality of the fermented millet. Effect of cereal combinations on chemical characteristics of fermented millet is shown in Table 3. Fermented mash containing $80 \%$ millet $+20 \%$ wheat (MW) had significantly higher moisture content of all the cereal combinations but the values between fermented mashes containing $80 \%$ millet $+20 \%$ rice (MR) and $80 \%$ millet $+10 \%$ rice $+10 \%$ wheat (MRW) were statistically not different ( $>005$ ). Sample MR had significantly higher moisture content than that of sample M (100\% millet). From Table 3 it can be seen that finger millet substituted with $20 \%$ of either rice or wheat significantly increased the moisture content of fermented cereals compared to control (100\% millet)

Cereal combinations showed a significant effect ( $>0.05$ ) on the TSS of fermented mashes. Millet substituted with $20 \%$ rice resulted the highest TSS $\left(14.60^{\circ} \mathrm{Bx}\right)$ while fermented millet containing $20 \%$ wheat had the lowest TSS $\left(9.67^{\circ} \mathrm{Bx}\right)$ of all the samples. It was found that addition of rice at both levels (10 and 20\%) significantly increased the TSS compared to control, whereas the TSS of samples MR and MRW were statistically not different.

Total and fixed acidities were in the range of 0.89 1.08 and $0.81-0.97 \% \mathrm{~m} / \mathrm{m}$ as lactic acid respectively, 
but the values were statistically not different $(p>0.05)$ indicating that cereal combination did not have a significant effect on total and fixed acid contents. Millet substituted with $10 \%$ each of wheat and rice (MRW) had the highest volatile acidity $(0.079 \% \mathrm{~m} / \mathrm{m}$ as acetic acid) of all the samples but the values among the rest three samples were statistically not different. Alcohol contents of fermented cereals were 14.11, 14.19, 14.12 and $14.41 \% \mathrm{v} / \mathrm{m}$ for samples M, MR, MW and MRW respectively, however, the values were statistically not different. Cereal combinations showed a significant effect on total ester content with a maximum value of $0.863 \mathrm{~g} / \mathrm{l}$ alc as ethyl acetate in $100 \%$ millet while a minimum value of $0.431 \mathrm{~g} / \mathrm{l}$ alc was found in fermented millet substituted with $20 \%$ of wheat. From Table 3 it is apparent that $20 \%$ wheat addition reduced the ester content by half, whereas addition of rice alone did not affect ester content compared to control (100\% millet). Increasing wheat content from $10 \%$ to $20 \%$ decreased the total ester content by about $34 \%$ in the fermented millet.

Total aldehyde content was significantly affected by cereal combinations. Fermented millet without cereal substitution (M) had the lowest total aldehyde content ( $0.698 \mathrm{~g} / \mathrm{l}$ alc as acetaldehyde) while a maximum value of $1.545 \mathrm{~g} / \mathrm{l}$ alc was found in fermented millet containing $20 \%$ rice. LSD indicated that the values of total aldehyde contents between samples $\mathrm{M}$ and MW and between MR and MRW were statistically not different. Incorporation of rice significantly increased the aldehyde content suggesting that aldehyde formation was favored by the presence of rice (Table 3)

Table 3. Effect of cereal combinations on the chemical characteristics of fermented cereals

\begin{tabular}{|c|c|c|c|c|}
\hline \multirow[t]{2}{*}{ Parameters } & \multicolumn{4}{|c|}{ Values for different cereal comb inations * } \\
\hline & $\mathbf{M}$ & MR & MW & MRW \\
\hline Moisture content $(\% \mathrm{~m} / \mathrm{m})$ & $70.78^{4}(0.41)$ & $7266^{b}(0.71)$ & $81.16^{6}(0.66)$ & $71.91^{4 b}(1.56)$ \\
\hline TSS, ${ }^{\circ} \mathrm{Bx}$ & $12.07^{\star}(0.90)$ & $14.60^{b}(0.46)$ & $9.67^{6}(0.12)$ & $14.10^{b}(0.3)$ \\
\hline Total acidity as lactic acid (\% mim) & $1.01^{\star}(0.02)$ & $0.89^{\star}(0.02)$ & $1.08^{\star}(0.07)$ & $1.03^{n}(0.01)$ \\
\hline Fixed acidityas lactic acid (\% m/m) & $0.97^{\star}(0.02)$ & $0.81^{\star}(0.04)$ & $0.95^{\wedge}(0.12)$ & $0.87^{n}(0.11)$ \\
\hline Volatile acidity as ace tic acid (\% m/m) & $\begin{array}{c}0.037^{\star} \\
(0.005)\end{array}$ & $0.044^{x}(0.019)$ & $0.043^{n}(0.011)$ & $0.079^{b}(0.009)$ \\
\hline Alcohol content $(\% \mathrm{wm})$ & $14.11^{n}(0.10)$ & $14.19^{x}(0.93)$ & $14.12^{n}(0.10)$ & $14.41^{\star}(0.72)$ \\
\hline Ester as ethyl acetate ( $\mathrm{g} / \mathrm{l} \mathrm{alc})$ & $\begin{array}{r}0.863^{\star} \\
(0.168)\end{array}$ & $0.814^{\star 6}(0.103)$ & $0.431^{b}(0.068)$ & $0.651^{\circ}(0.061)$ \\
\hline Aldehydes as ace taldehyde ( $g / 1 \mathrm{alc}$ ) & $\begin{array}{r}0.698^{A} \\
(0.053)\end{array}$ & $1.545^{b}(0.224)$ & $0.901^{\star}(0.078)$ & $1.275^{b}(0.169)$ \\
\hline Fusel oil ( $g / 1 \mathrm{alc})$ & $\begin{array}{c}6.277^{4} \\
(0.395)\end{array}$ & $9.370^{b}(0.582)$ & $5.297^{\circ}(0.325)$ & $7.335^{\mathrm{d}}(0.673)$ \\
\hline Methanol ( $g / l \mathrm{alc}$ ) & $\begin{array}{r}2.346^{\circ} \\
(0.162)\end{array}$ & $2.873^{n}(0.444)$ & $3.858^{x}(0.361)$ & $3.839^{\star}(0.261)$ \\
\hline Reducing sugar as dextrose $(\% \mathrm{~m} / \mathrm{m})$ & $5.98^{A}(0.18)$ & $10.01^{b}(0.55)$ & $2.04^{6}(0.02)$ & $7.48^{d}(0.17)$ \\
\hline Sucrose (\% m/m) & $1.62^{n}(0.25)$ & $0.78^{b}(0.44)$ & $0.82^{b}(0.01)$ & $1.34^{n}(0.05)$ \\
\hline Total sugar $(\% \mathrm{~m} / \mathrm{m})$ & $7.62^{\star}(0.09)$ & $10.8^{b}(0.31)$ & $2.86^{\circ}(0.03)$ & $8.82^{\mathrm{d}}(0.22)$ \\
\hline
\end{tabular}

$\mathrm{V}$ alues are the means of three determinations. Figures in the parentheses are the standard deviations. Means followed by different super scripts in a row are significantly different $(\mathrm{p}<0.05)$ by LSD.

\section{Sample notation:}

$\mathrm{M}=100 \%$ millet $\mathrm{MR}=80 \%$ millet $+20 \%$ rice $10 \%$ rice $+10 \%$ wheat
$\mathrm{MW}=80 \%$ millet $+20 \%$ wheat $\mathrm{MRW}=80 \%$ millet + 
Fusel oil content in the fermented mash was significantly influenced by cereal combination and was found to increase with increasing the proportion of rice in the fermentation mash while a reverse was found in the case of wheat where fermented millet containing $20 \%$ wheat had the lowest fusel oil content $(5.297 \mathrm{~g} / \mathrm{L}$ alc) of all the treatment combinations. Methanol content in the fermented mashes was in the range of $2.346-3.858 \mathrm{~g} / \mathrm{L}$ alc with an average value of $3.229 \mathrm{~g} /$ $\mathrm{L}$ alc, however the values were statistically not different.

There was a wide variation in the total reducing sugar contents among four samples with a minimum value of $2.04 \% \mathrm{~m} / \mathrm{m}$ as dextrose in $20 \%$ wheat incorporated sample and a maximum value of $10.01 \%$ in $20 \%$ rice substituted sample. LSD showed that addition of rice at both levels (10 and 20\%) significantly increased $(\mathrm{p}<0.05)$ the reducing sugar contents over the control (100\% millet). Furthermore, $20 \%$ addition of rice nearly doubled the reducing sugar content, while 20\% addition of wheat reduced the reducing sugar content by half to that of control. Reducing sugar content in the fermented mash was found to be largely dependent on the extent of rice incorporation. Total sugar content in the fermented cereal also followed similar trend to that of reducing sugar. Addition of both rice and wheat at $20 \%$ significantly decreased the sucrose content in the fermented mash over the control but the values between the former two samples were statistically not different. Similarly, the sucrose contents between samples M $(1.62 \% \mathrm{~m} / \mathrm{m})$ and MRW $(1.34 \% \mathrm{~m} / \mathrm{m})$ were not different.

The obtained values of methanol contents were analogous to that reported in wines $(2 \mathrm{~g} / \mathrm{L}$ alc) but were very low compared to fruit brandy ( $10 \mathrm{~g} / \mathrm{L}$ alc) as reported by Kirk and Sawyer (1991). Kirk and Sawyer (1991) reported that the minimum and maximum fusel oil contents in different brandy samples were 146 and $782 \mathrm{~g} / \mathrm{L}$ alc respectively which agreed to our findings. According to Cronk et al. (1979) the fusel oil content in rice fermented at $30{ }^{\circ} \mathrm{C}$ for $96 \mathrm{~h}$ using Amylomyces rouxii in combination of various yeasts was in the range of $4.714-6.740 \mathrm{~g} / \mathrm{L}$ alc which is in agreement with our results.
Except in fermented millet (M) all other fermented cereals had higher total aldehyde contents than those reported in brandy samples $(0.24-0.762 \mathrm{~g} / \mathrm{l}$ alc as acetaldehyde). The obtained values of total esters in our study were lower than those reported in brandy (1.12 - $5.80 \mathrm{~g} / \mathrm{l}$ alc as ethyl acetate) (Kirk \& Sawyer, 1991). Cronk et al. (1979) also reported that total ester contents in rice fermented using Amylomyces rouxii in combination with Hansenula anomala and $H$. subpelliculos $a$ at $30^{\circ} \mathrm{C}$ for $96 \mathrm{~h}$ were 26.843 and 21.548 $\mathrm{g} / \mathrm{l}$ alc as ethyl acetate respectively which were quite higher than those obtained in this study.

Effect of cereal combinations on the sensory quality of jands is depicted in Fig. 3. Mean sensory scores for colour, out of a possible total score of 9, were 7.86, 8.0, 7.29 and 7.14 for jands prepared from samples $M$, MR, MW and MRW respectively, however, the values were statistically not different indicating that cereal combination had no significant effect $(p>0.05)$ on the colour preference of jand. Mean sensory scores for taste were found to be 8.71, 8.14, 6.71 and 6.86 respectively for samples $\mathrm{M}, \mathrm{MR}, \mathrm{MW}$ and MRW respectively. Statistical analysis showed that cereal combinations had a significant effect $(\mathrm{p}<0.05)$ on the taste preference of jand. LSD indicated that the mean taste scores between samples M and MR (liked very much) and between MW and MRW (liked slightly) were not different while the former two samples had higher taste scores compared to latter two. Incorporation of wheat at either levels (10 and 20\%) significantly decreased the taste preference of jand. Similarly, mean smell scorers were 7.71, 7.86, 7.0 and 6.86 for samples M, MR. MW and MRW respectively. Statistically, the scores between samples M and MR and between MW and MRW did not differ. Similarly, jands prepared from samples M and MW were equally preferred based on smell. From Fig. 3 it revealed that $10 \%$ addition of wheat significantly reduced the smell preference of millet jand compared to jands obtained from control (100\% millet) and $20 \%$ rice incorporated fermented millet.

\section{Sample notation}

$\mathrm{M}=100 \%$ millet $\mathrm{MR}=80 \%$ millet $+20 \%$ rice $\mathrm{MW}=$ $80 \%$ millet $+20 \%$ wheat $\mathrm{MRW}=80 \%$ millet $+10 \%$ rice $+10 \%$ wheat 


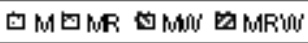

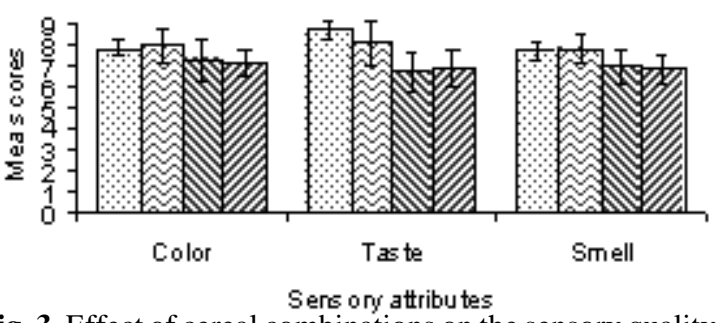

Fig. 3. Effect of cereal combinations on the sensory quality of millet jand*.

$*$ : Values are the means $(\mathrm{n}=10) \pm \mathrm{SD}$. Bars having different letters for any quality attributes are significantly different $(\mathrm{p}<0.05)$ by LSD.

\section{Conclusions}

Finger millet fermented in plastic and wooden containers had better chemical characteristics than that of earthen container, whereas sensory quality of millet jands was not influenced by fermentation containers. Plastic containers could be regarded as an appropriate container for cereal fermentation because of their ease of cleaning and handling. Except for total acidity and ester contents, other chemical characteristics of millet, rice, maize and wheat jands were not significantly different $(\mathrm{p}<0.05)$. Organoleptic quality of rice jand was highly preferred, while that of maize was least preferred among millet, rice, maize and wheat jand samples. However, the selection of cereal for fermentation is largely dictated by the end use: rice being suited for strained jand making while millet for toongba preparation.

Substitution of finger millet with rice and wheat, singly or in combination, did not affect alcohol and methanol contents in the fermented mash. Total ester content substantially decreased by wheat incorporation whereas total aldehyde content increased by rice incorporation compared to control (100\% finger millet). Incorporation of rice seemed to favour the production of fusel oil while that of wheat alone decreased its content. Cereal combination showed no significant effect on the color but incorporation of wheat significantly reduced the taste and smell preference of jand. On the whole, no remarkable improvement on the chemical and sensory quality of fermented millet was found by cereal combination over the control.

\section{References}

Amerine, M.A. and W.V. Cruess. 1960. The technology of wine making, $2^{\text {nd }}$ Edn. AVI Publishing Co., Westport Connecticut.

AOAC. 2005. Official methods of analysis of AOAC international, $18^{\text {th }}$ Edn. AOAC

International Suite Gaithersburg, Maryland, USA.

Berry, D.R. and D.C.Watson. 1987. Production of organoleptic compounds. In: Berry,

D.R., I. Russell, and G.G. Stewarts. (Eds). Yeast biotechnology. Elsevier Applied

Science Publishers, London, New York

Buysse, W., R. Stern., R. Coe, and C. Matere. 2007. Genstat discovery edition 3 for

everyday use. ICRAF Nairobi, Kenya.

Cronk, T.C., L.R., Mattick, K.H. Steinkraus, and L.R. Hackler. 1979. Production of higher

alcohol during the Indonesian tape ketan fermentation. Applied Environmental

Microbiology, 37: 892-896. In: Steinkraus, K.H. 1995. Handbook of indigenous

fermented foods, $2^{\text {nd }}$ Edn. Marcel Dekker, New York. pp. 462-463.

Kirk, R.S. and R. Sawyer. 1991. Pearson's composition and analysis of foods, $9^{\text {th }} \mathrm{Edn}$.

Addision Wesley Longman Ltd., Edinburgh Gate, Harlow, England.

Lee, C.H. and G.M. Kim. 1993. Korean rice-wine, the types and processing methods in old

Korean literature. Bioindustry, 6(4): 8-25.

Peynaud, E. 1937. Etudes ser les phenomenes d'esterification. Rev. Viticult. 86: 209-475.

In: Zoecklein, B.W., Fugelsang, K.C., Gump, B.H. and Nury, F.C. 1997. Wine

analysis and production. CBS Publishers and Distributors, New Delhi, India.

Rai, B.K. (2006). Preparation of fermentation starter culture using yeasts and molds isolated

from local murcha. M. Tech. (Food) Dissertation, Central Department of Food

Technology, Tribhuvan University, Nepal.

Rai, B.K (1991). Preparation and quality evaluation of jand from malted and unmalted

millet (kodo) using A. oryzae and S. sake. B. Tech (Food) Dissertation, Central

Campus of Technology, Tribhuvan University, Nepal.

Ranganna, S. 1986. Handbook of analysis and quality Control for fruit and vegetable

products, $2^{\text {nd }}$ Edn. Tata McGraw-Hill Publishing Co., Limited, India.

Ross, R.P., S. Morang, and C. Hill. 2002. Preservation and fermentation: past, present and

future. International Journal of food Microbiology, 79: 3-16. 
Dhan B. Karki \& ganga P. Kharel/Effect of Fermentation.......

Upadhyaya, A. (2005a). Effect of raw materials on the quality of jand. B. Tech. (Food)

Dissertation, Central Campus of Technology, Tribhuvan University, Nepal.

Venkataramu, K. and C. Bassapa. 1993. A comparative study of chhang fermentation of

ragi using natural (traditional) and pure microbial inocula. IFCON 1993 Poster

Sessions Abstract, AFST (India). p. 65.

Yoon, S.S. 1993. ChenMin Yosul. A Translation of ChiMin-Yao-Shu in Korean.
MinEumsa, Seoul, Korea. In: Fermented cereals: A global perspective. FAO

Agricultural Services Bulletin No. 38. Food and Agriculture Organization of the

United Nations, Rome (1999). p. 74

Zoecklein, B.W., K.C. Fugelsang, B.H., Gumpand and F.C. Nury. 1997. Wine analysis and

production. CBS Publishers and Distributors, New Delhi, India. 
Nepal Journal of Science and Technology 12 (2011) 330-339 